\title{
BMJ Open How much emergency department use by vulnerable populations is potentially preventable?: A period prevalence study of linked public hospital data in South Australia
}

\author{
David Banham, ${ }^{1,2}$ Jonathan Karnon, ${ }^{1}$ Kirsten Densley, ${ }^{3}$ John W Lynch ${ }^{1}$
}

To cite: Banham D, Karnon J, Densley K, et al. How much emergency department use by vulnerable populations is potentially preventable?: A period prevalence study of linked public hospital data in South Australia. BMJ Open 2019;9:e022845. doi:10.1136/ bmjopen-2018-022845

- Prepublication history and additional material for this paper are available online. To view these files, please visit the journal online (http://dx.doi org/10.1136/bmjopen-2018022845).

Received 15 March 2018 Revised 11 December 2018 Accepted 13 December 2018

Check for updates

(C) Author(s) (or their employer(s)) 2019. Re-use permitted under CC BY-NC. No commercial re-use. See rights and permissions. Published by BMJ.

${ }^{1}$ School of Public Health, Faculty of Health and Medical Sciences, The University of Adelaide, Adelaide, South Australia, Australia

${ }^{2}$ Division of Health Sciences, University of South Australia, Adelaide, South Australia,

Australia

${ }^{3}$ Flinders Medical Centre, Southern Adelaide Local Health Network, Bedford Park, South Australia, Australia

Correspondence to Mr David Banham; david.banham@sahmri.com

\section{ABSTRACT}

Objectives To quantify emergency department (ED) presentations by individuals within vulnerable populations compared with other adults and the extent to which these are potentially preventable.

Design Period prevalence study from 2005-2006 to 20102011.

Setting Person-linked, ED administrative records for public hospitals in South Australia.

Participants Adults aged 20 or more in South Australia's metropolitan area presenting to ED and categorised as Refugee and Asylum Seeker Countries of birth (RASC); Aboriginal; those aged 75 years or more; or All others. Main outcome measures Unadjusted rates of ambulatory care sensitive condition (ACSC), general practitioner (GP)type presentations and associated direct ED costs among mutually exclusive groups of individuals.

Results Disparity between RASC and All others was greatest for GP-type presentations (423.7 and 240.1 persons per 1000 population, respectively) with excess costs of \$A106573 (95\% Cl \$A98 775 to \$A114 371) per 1000 population. Aboriginal had highest acute ACSC presenter rates (125.8 against 51.6 per 1000 population) with twice the risk of multiple presentations and \$A108701 (95\% CI \$A374 to \$A123029) per 1000 excess costs. Those aged 75 or more had highest chronic ACSC presenter rates (119.7vs21.1 per 1000), threefold risk of further presentations (incidence rate ratio 3.20 , $95 \% \mathrm{Cl} 3.14$ to 3.26$)$ and excess cost of $\$ A 385$ (95\% Cl \$A178160 to \$A184609) per 1000 population. Conclusions Vulnerable groups had excess ED presentations for a range of issues potentially better addressed through primary and community healthcare. The observed differences suggest inequities in the uptake of effective primary and community care and represent a source of excess cost to the public hospital system.

\section{BACKGROUND}

Australia's public hospital emergency department (ED) presentations are increasing faster $^{12}$ than the populations they serve. ${ }^{13}$ This is an intractable concern for state and territory $^{45}$ health departments responsible for providing public hospital services.
Strengths and limitations of this study

- This is the first study to examine variations in potentially preventable emergency department (ED) presentations and direct hospital costs among several vulnerable populations in Australia.

- The study uses person-linked public hospital records over a 6-year period from 2005 to 2006 to 2010-2011.

- The study informs health system performance measurement focused on vulnerable populations' capacity to benefit from preventative and community-based services.

- Our analysis was limited by the omission of one ED site representing approximately $10 \%$ of ED activity.

- The ED presenting diagnoses used to categorise potentially preventable presentations can be the subject of reclassification.

Effective and efficient responses to the issue will involve the health system providing the best care at the time of first contact with a person. ${ }^{6}$ The development of such responses will benefit from a system-wide understanding of who uses ED services and what care alternatives are needed.

We know from previous research that ED presentations for acute, chronic and vaccine-preventable conditions such as urinary tract infections, asthma and influenza are potentially suited to primary and community healthcare interventions and can be collectively quantified as ambulatory care sensitive conditions (ACSCs). ${ }^{7-15}$ As such, ACSCs are widely used as indicators of suboptimal availability and effectiveness of primary healthcare in reducing the need for hospital care through primary prevention, early diagnosis, treatment and/or appropriate management in community settings. ${ }^{16}$ A related measure is potentially avoidable general practice, or 
general practitioner (GP)-type presentations ${ }^{17} 18$ which comprises lower acuity ED presentations not resulting in hospitalisation. ACSC and GP-type presentations may also reflect systemic inequities in accessing relevant, effective services. ${ }^{1920}$ Either way, ED use is associated with financial cost to the health system and costs to individuals experiencing disruption, stress and crises, and discontinuity of care, particularly for chronic conditions. Previous analyses of administrative records have also identified several groups vulnerable to excess contact with hospitals generally. These population groups include those from Refugee and Asylum Seeker Countries (RASCs), ${ }^{20-23}$ Aboriginal people (where 'Aboriginal' is respectfully used to refer to people self-identifying as Aboriginal, Torres Strait Islander or both ${ }^{2024}$ ) and those aged 75 years or more..$^{24}$

Descriptions of ED activity among RASC, ${ }^{21}{ }^{26}$ Aboriginal $^{27}$ and older Australians, ${ }^{128}$ and the extent to which the activity is potentially preventable, are limited. In those that are available, the unit of analysis was ED presentations rather than unique individual presenters. Reframing ED activity information to describe outcomes for individuals within vulnerable populations will provide important new information. For example, understanding the number of individuals presenting to EDs, and the likelihood of their having multiple presentations, will better detail their capacity to benefit from services suiting their condition or circumstance. ${ }^{29}$ Detailing direct service costs will then help scope the potential for redirecting resources from high cost acute environments towards preventative measures and care in community settings.

Our aim is to provide such information by quantifying the use of public hospital EDs by three vulnerable populations in comparison with the rest of the population in metropolitan South Australia. Our objectives in doing so are first to quantify the rates of public ED presentations overall, and those involving ACSC and GP-type presentations. We then quantify the comparative rates with which individuals within population groups presented to EDs once or multiple times, together with the direct, system cost of these presentations. In each instance, we stratify results for ED presentations overall to report on ACSC and GP-type presentations.

\section{METHODS}

\section{Patient and public involvement}

This study did not directly involve patients and the public in its design and conduct. Rather, the study's research questions, design and outcome measures had their genesis in a community of practice (CoP) focused on population health analyses. CoP members included service managers and policy officers who shared anecdotes of unmet need among specific population groups while also reflecting on the lack of systematic evidence on their service use, including ED, leading to gaps in supporting service planning. DB undertook to help address this information need in support of patient-focused service planning. The results have been actively disseminated through public and professional meetings including the CoP, South Australia (SA) Primary Health Networks, the Australian Health Economics Society, the Health Service Research Association of Australia and New Zealand, and Australia's Population Health Congress, while also formally offered to SA Health, the state government's lead health agency and published in a freely accessible journal.

\section{Study design}

Period prevalence study using person-linked, public hospital ED administrative records from 2005 to 2006 to 2010-2011 in Adelaide, South Australia.

\section{Data sources}

\section{Study populations}

South Australia is situated in southern, central Australia and the Adelaide metropolitan area is home to $70 \%$ of the population. ${ }^{30}$ We used Australia's Census years in 2006 and $2011^{3}$ to disaggregate this population into mutually exclusive categories comprising three vulnerable groups and an 'All other' comparator using the following criteria. RASC included people whose country of birth involved $50 \%$ or more of the population arriving on humanitarian visas in the decade to 2011 as reported in the Australian Government's Settlement Reporting Facility $^{21}$ (see online supplementary table A). Aboriginal included those self-identifying as such. Five-year age groupings enabled enumeration of those aged 75 years or more, and this group included any person regardless of RASC or Aboriginality. A lower age limit of 20 years was also applied, meaning the 'All others' group comprised adults aged 20 to 74 years who were not otherwise included in RASC or Aboriginal groups. Census 2011 also provided the Index of Relative Socioeconomic Disadvantage (IRSD), ${ }^{31}$ an area-level measure of socioeconomic disadvantage. Total population were thus distributed to disadvantage quintiles of approximately equal population size $^{32}$ ranked as Quintile 1 Least disadvantage to Quintile 5 Most disadvantage.

These Census' data provided the basis of population denominators for adults aged 20 years or more. We used 'All others' as the comparison group. Separate denominators were determined for RASC aged 20 to 74 years, Aboriginal aged 20 to 74 years, those aged 75 years or more, and 'All others' (as online supplementary table B).

\section{ED presentations for individuals}

All presentations to six public hospital EDs (Royal Adelaide, The Queen Elizabeth, Lyell McEwin and Repatriation Hospitals; Flinders Medical Centre and Noarlunga Health Service) were available to the study. One further hospital was omitted having transferred between private and public administration within the observation period.

Person-level analysis was facilitated by linked project keys from SA-NT DataLink which enabled the grouping of each person's presentations across hospitals and time. We retained records for persons aged 20 years or more living 
in the metropolitan area. Each individual's records took on the country of birth, Aboriginal self-identification, age and metropolitan area-level socioeconomic disadvantage quintile recorded in that person's first occurring, index presentation.

Accordingly, all individuals aged 20 years or more and presenting to EDs were categorised to one of the mutually exclusive study groups in the same manner as described for population denominators, that is, RASC aged 20 to 74 years, Aboriginal aged 20 to 74 years, those aged 75 years or more, and 'All others' with the remainder of those aged 20 to 74 years.

\section{ED presentations type and cost}

ACSC categorisation of International Statistical Classification of Diseases and Related Health Problems 10th revision (ICD-10) ${ }^{33}$ presentation diagnoses followed the Australian standard classification for ACSC published by the Australian Institute of Health and Welfare. ${ }^{34}$ The relevant diagnoses for ACSC categories and conditions are available as online supplementary table C. Potentially avoidable GP-type presentations were defined using Australia's National Healthcare Agreement performance indicator specification of Triage 4 or 5; excluding arrival by ambulance or police; and not subsequently admitted, transferred or deceased. ${ }^{1718}$

The Australian public health system uses activity-based funding to reimburse hospitals. Each ED presentation is associated with a hospital activity Urgency Related Group (URG V.1.4) code and weighting that reflects the triage level, diagnosis and end status. The URG weighting for a presentation is multiplied by a standard, National Efficient Pricing (NEP) amount to determine the reimbursement to the ED for that presentation. We uniformly used the NEP of \$A5007 for 2014-2015 ${ }^{35}$ for all presentations in our analysis. As an example, a walk-in presentation of Triage level 2 for R074 (unspecified chest pain) with a weighting of 0.2311 equates to a direct cost of $\$ A 1157$. Presentations for Aboriginal people had an additional 4\% loading in recognition of factors such as more frequent comorbidities which contribute to higher investigation or treatment costs. The cost of any ensuing inpatient stays were not included in this analysis.

\section{Data analysis}

We present the number of ED presentations together with the crude, unadjusted rate of presentations among each vulnerable group and the comparator group. Similarly, we report the number and rate of persons within each group who presented to EDs. The total person numbers were disaggregated by the number of ED presentations made and are reported with their associated population rates. We further describe the proportion of group members attending ED by sex, age group and area-level IRSD quintiles. The number of persons within each group who had ACSC presentations (total; acute, chronic and vaccine) or GP-type presentations are then described as a proportion of total group presenters and as a population rate.
The likelihood of individuals in each vulnerable group having more than one ED presentation compared with the 'All others' group was assessed using stratified Poisson regression models and the results reported as incidence rate ratios (IRR). The cost of ED presentations (total, ACSC and its categories, and GP type) were totalled for each person presenting to EDs and the mean cost for presenters within each group was calculated. We assessed excess cost in a vulnerable group as the difference in total cost per 1000 population (the product of mean cost by number of presenters per 1000 population) in that group compared with the comparator group and provide a worked example of the relevant table as an online supplement. All analyses used Stata V.15.1.

\section{RESULTS \\ Population groups}

The vulnerable population groups studied made up $11.6 \%$ of the Adelaide metropolitan area total comprising RASC $0.6 \%$, Aboriginal $1.0 \%$ and those aged 75 or more $10.0 \%$.

\section{Presentations and persons presenting to EDs}

ED presentation rates by vulnerable groups and the characteristics of those individuals presenting are summarised in table 1. Collectively, one in five $(21.6 \%)$ ED presentations involved vulnerable group members. RASC, Aboriginal and those aged 75 or more each had higher presentation rates compared with the All others group. Underlying this were both higher rates of individual persons presenting and presenting multiple times. RASC had the youngest age profile with $60 \%$ of presenters aged under 35 years and a higher likelihood of living in comparatively disadvantaged areas (61\% from the most disadvantaged Quintiles 4 and 5 vs $40 \%$ of All others). Younger adults also featured among Aboriginal presenters (50\% aged under 35 years) with an even higher concentration in socioeconomically disadvantaged areas (69\% from Quintiles 4 and $5)$. Older presenters aged 75 or more were no more likely to live in disadvantaged areas than those in the All others group.

\section{Persons presenting for ACSC and GP-type presentations}

Vulnerable group members having ACSC and GP-type presentations are summarised in table 2. Each vulnerable group had markedly higher presenter rates for ACSC compared with the All others group. In particular, Aboriginal people and those aged 75 years or more had presentation rates at least twice that of the comparator group (rate ratio (RR) 2.16, 95\% CI 1.62 to 2.89 and $2.88,95 \%$ CI 2.18 to 3.80 , respectively). There was more variation in the rates with which individuals in groups presented across ACSC categories. For example, in instances of acute ACSC, each of the groups had rates of individual presenters that were around twice that of the comparator group. Where chronic ACSCs were involved, however, those aged 75 years or more had fivefold higher 


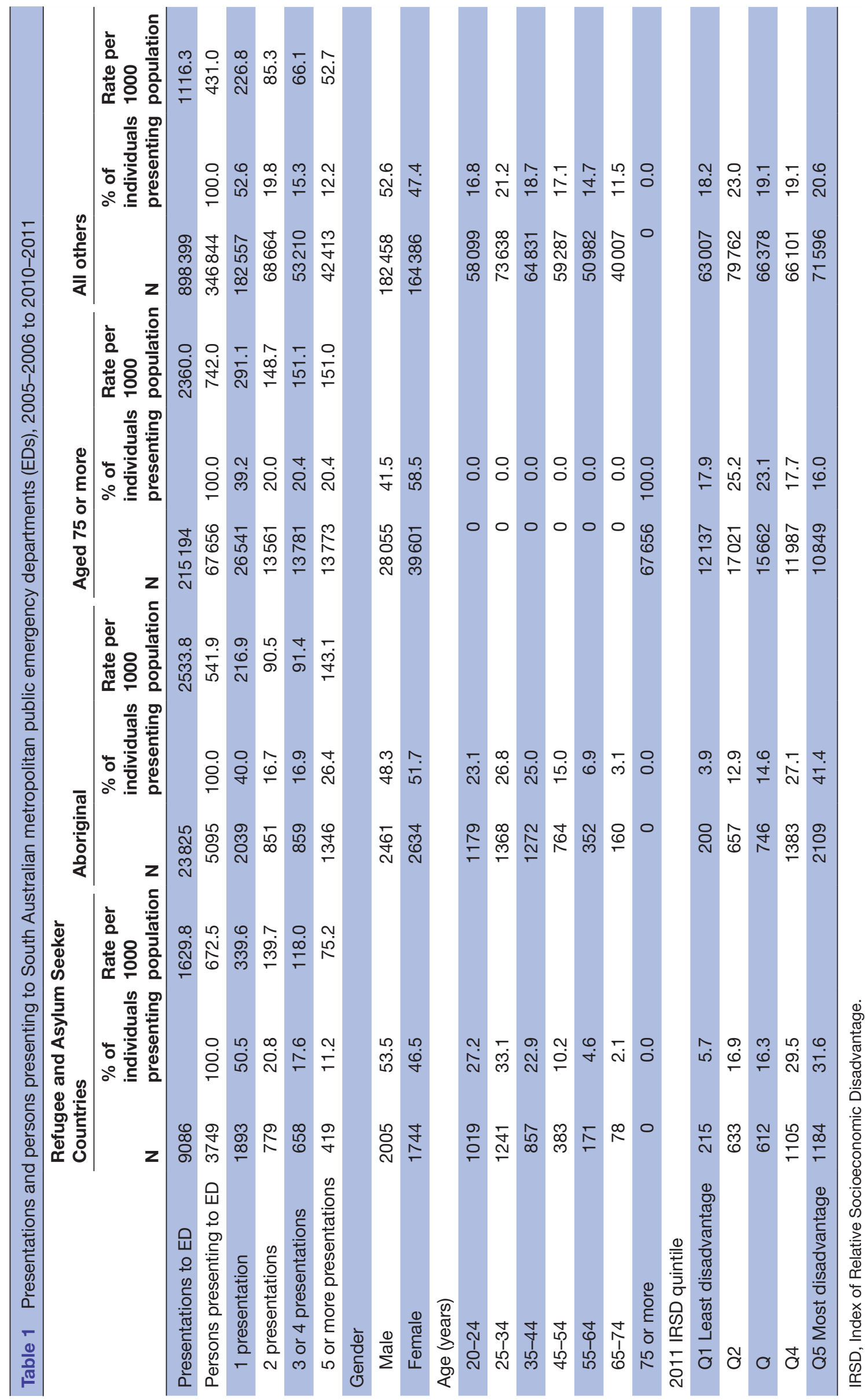


Table 2 Persons presenting with ACSC and GP-type presentations to South Australian metropolitan public ED, 2005-2006 to 2010-2011

\begin{tabular}{|c|c|c|c|c|}
\hline & $\begin{array}{l}\text { Persons } \\
\text { presenting (N) }\end{array}$ & $\begin{array}{l}\% \text { of persons } \\
\text { within group }\end{array}$ & $\begin{array}{l}\text { Persons presenting } \\
\text { per } 1000 \text { population }\end{array}$ & $\begin{array}{l}\text { Rate ratio } \\
\text { (vulnerable group: All } \\
\text { others) }(95 \% \mathrm{Cl})\end{array}$ \\
\hline \multicolumn{5}{|l|}{ ACSC presentations* } \\
\hline Refugee and Asylum Seeker Countries & 734 & 19.6 & 131.7 & 1.84 (1.37 to 2.48$)$ \\
\hline Aboriginal & 1454 & 28.5 & 154.6 & 2.16 (1.62 to 2.89$)$ \\
\hline Aged 75 or more & 18823 & 27.8 & 206.4 & 2.88 (2.18 to 3.80$)$ \\
\hline All others & 57670 & 16.6 & 71.7 & Reference \\
\hline \multicolumn{5}{|l|}{ ACSC (acute) ${ }^{\star}$} \\
\hline Refugee and Asylum Seeker Countries & 619 & 16.5 & 111.0 & 2.15 (1.52 to 3.03$)$ \\
\hline Aboriginal & 1183 & 23.2 & 125.8 & $2.44(1.74$ to 3.41$)$ \\
\hline Aged 75 or more & 9739 & 14.4 & 106.8 & 2.07 (1.46 to 2.92$)$ \\
\hline All others & 41505 & 12.0 & 51.6 & Reference \\
\hline \multicolumn{5}{|l|}{ ACSC (chronic) ${ }^{*}$} \\
\hline Refugee and Asylum Seeker Countries & 105 & 2.8 & 18.8 & $0.89(0.46$ to 1.77$)$ \\
\hline Aboriginal & 391 & 7.7 & 41.6 & 1.97 (1.16 to 3.56$)$ \\
\hline Aged 75 or more & 10916 & 16.1 & 119.7 & 5.68 (3.57 to 9.57$)$ \\
\hline All others & 16965 & 4.9 & 21.1 & Reference \\
\hline \multicolumn{5}{|l|}{ ACSC (vaccine) $)^{*}$} \\
\hline Refugee and Asylum Seeker Countries & 42 & 1.1 & 7.5 & 2.28 (0.53 to 13.98$)$ \\
\hline Aboriginal & 34 & 0.7 & 3.6 & 1.09 (0.23 to 9.10$)$ \\
\hline Aged 75 or more & 238 & 0.4 & 2.6 & 0.79 (0.11 to 4.43$)$ \\
\hline All others & 2662 & 0.8 & 3.3 & Reference \\
\hline \multicolumn{5}{|l|}{ GP-type presentations* } \\
\hline Refugee and Asylum Seeker Countries & 2362 & 63.0 & 423.7 & 1.76 (1.50 to 2.08$)$ \\
\hline Aboriginal & 2896 & 56.8 & 308.0 & 1.28 (1.08 to 1.53$)$ \\
\hline Aged 75 or more & 15154 & 22.4 & 166.2 & 0.69 (0.56 to 0.85$)$ \\
\hline All others & 193249 & 55.7 & 240.1 & Reference \\
\hline
\end{tabular}

As a person may present more than one time for more than one category, the sum of persons at category level may not equal the total number of persons having presented.

${ }^{*} \mathrm{ACSC}$, ambulatory care sensitive condition; ED, emergency department; GP, general practitioner.

rates (RR 5.68, 95\% CI 3.57 to 9.57 ) while rates in the Aboriginal population remained around twice that of the comparator group. RASC were relatively less represented.

GP-type presenter rates were higher than the comparator group for Aboriginal people (RR 1.28, 95\% CI 1.08 to 1.53 ) and higher again among RASC with RR 1.76 (95\% CI 1.50 to 2.08). Conversely, rates were markedly lower among those aged 75 years or more with RR 0.69 (95\% CI 0.56 to 0.85$)$. Online supplementary table $\mathrm{D}$ includes description for selected acute and chronic conditions.

\section{Risk of multiple presentations}

Figure 1A through $1 \mathrm{~F}$ report the rates with which individuals had a single presentation, then those having two or more presentations. We also report the average likelihood (as an IRR) of individuals having multiple presentations compared with those in the All others group.
RASC had the highest rates of single ED presenters overall while those aged 75 or more had the highest rates of individuals with multiple presentations. Of all the groups, Aboriginal people had the highest likelihood of repeated presentations compared with All others (IRR $1.8195 \%$ CI 1.78 to 1.83 ). While the rates of individuals presenting for any ACSC were highest among those aged 75 or more, Aboriginal presenters were most likely to have two or more presentations (IRR 2.22, 95\% CI 2.14 to 2.30). In acute ACSC, we found Aboriginal people again had the highest likelihood of multiple presentations with IRR 2.41 (95\% CI 2.31 to 2.52). They also had elevated likelihood of multiple presentations for chronic ACSC conditions; however, this category was dominated by those aged 75 or more where single and multiple presenter rates were highest. Indeed, those aged 75 or more had a threefold higher risk of multiple chronic ACSC presentations 
A Any presentation
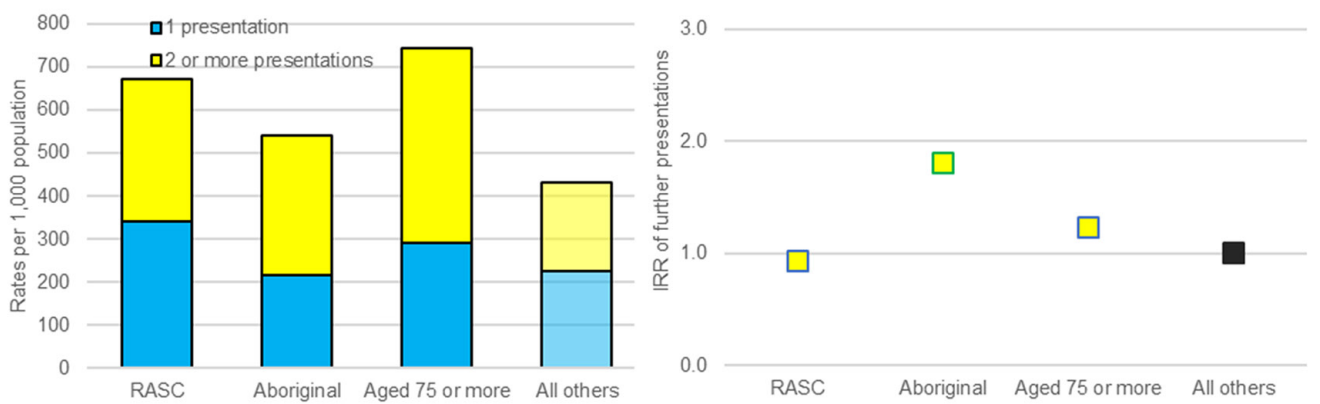

B ACSC
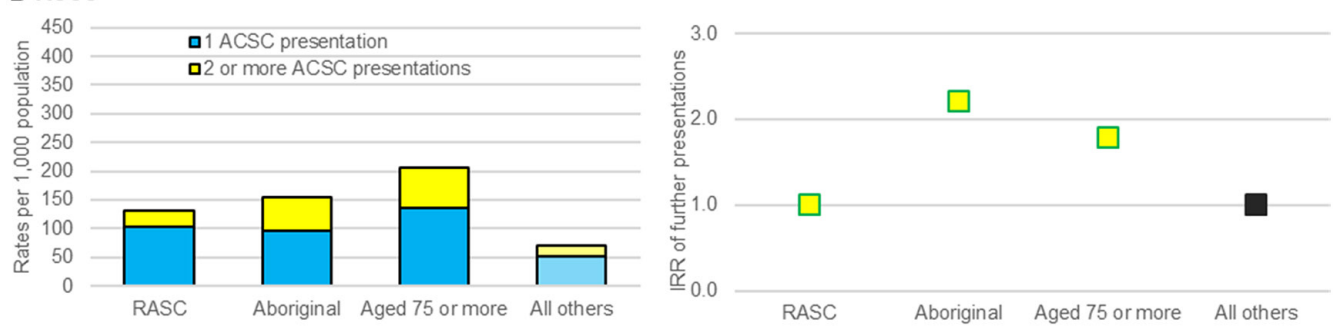

C Acute ACSC
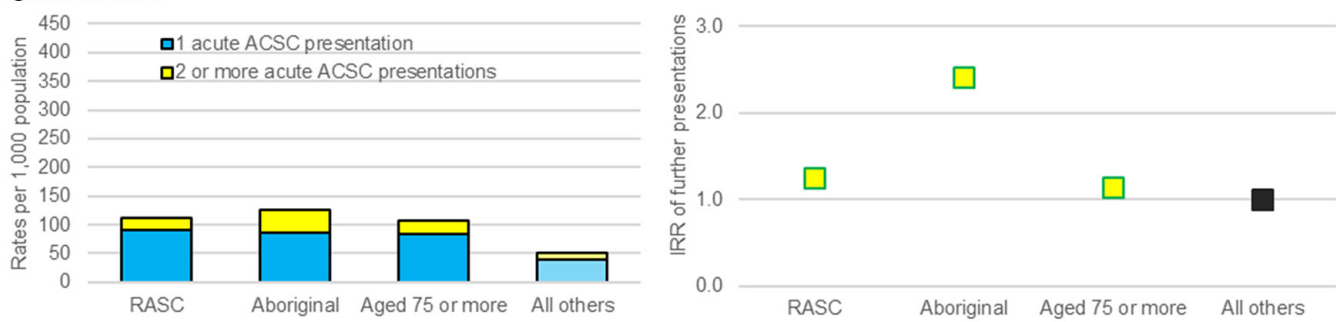

D Chronic ACSC
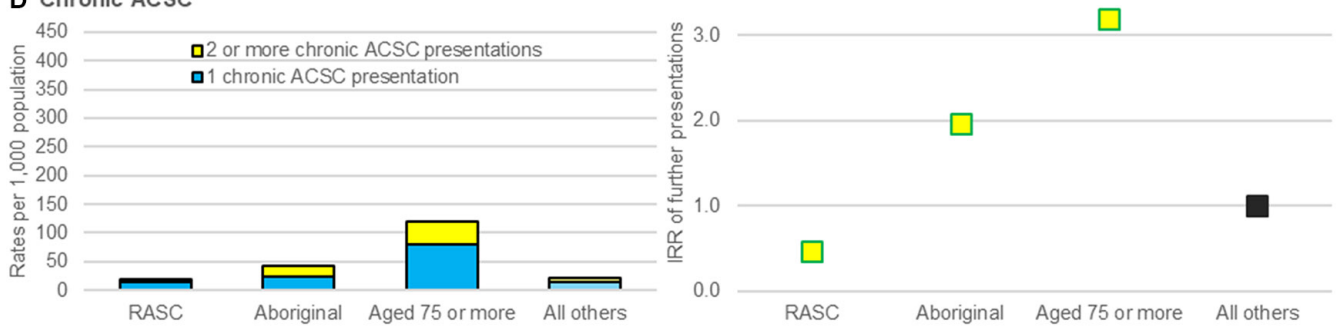

E Vaccine ACSC
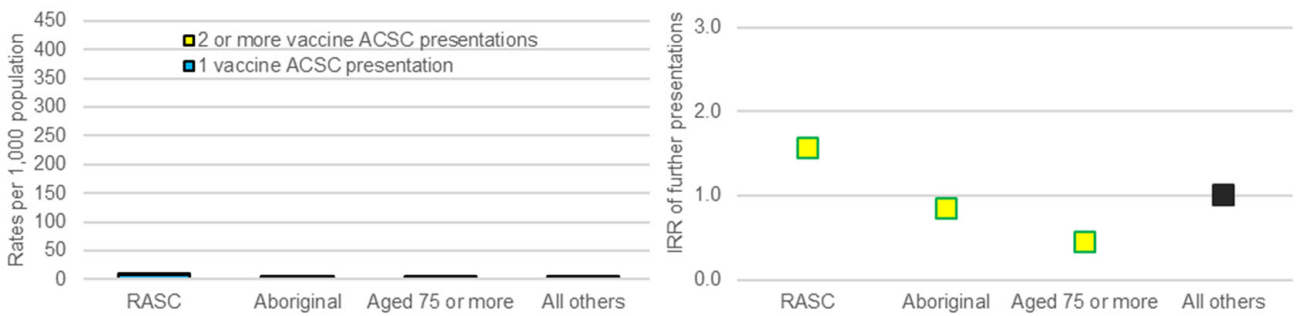

F GP-type
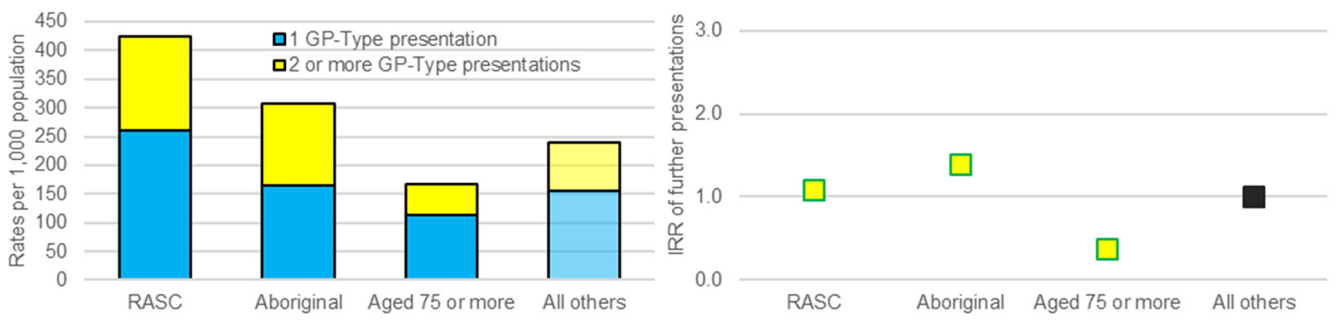

Figure 1 Rates of persons presenting to ED and the relative likelihood of subsequent presentation, South Australian public hospitals 2005-2006 to 2010-2011. ACSC, ambulatory care sensitive condition; GP, general practitioner; IRR, incidence rate ratio; RASC, Refugee and Asylum Seeker Country. 
compared with All others (IRR 3.20, 95\% CI 3.14 to 3.26). RASC and Aboriginal had the highest rates of individuals with two or more GP-type presentations, while Aboriginal individuals also had the greatest risk of multiple presentations, IRR 1.39 (95\% CI 1.35 to 1.42).

\section{Excess costs of ED presentations}

In total, approximately $\$$ A22 million per year was associated with excess ED presentations by vulnerable groups. Table 3 contrasts observed costs among vulnerable groups per 1000 population with All others to show progressively higher excess costs for RASC, Aboriginal populations and those aged 75 or more (\$A250 332, \$A1 020878 and $\$ 1314231$, respectively). We provide a worked example of our calculations in online supplementary table E.

Excess costs attributed to potentially preventable presentations for ACSC and GP-type categories totalled \$A4.2 million and \$A280000 annually. Their contribution to excess group costs also varied substantially. While individual RASC presenters accrued lower mean presentation costs, higher presenter rates led to excess costs of \$A106573 per 1000 population for GP-type presentations and \$A22524 for ACSC, the latter heavily influenced by acute conditions. Excess cost rates for Aboriginal people increased from chronic ACSC to acute ACSC to GP-type presentations. Among people aged 75 or more, ACSC costs featured more than twofold greater rates for chronic conditions than acute.

\section{DISCUSSION}

We compared the average rates which RASC, Aboriginal and older persons populations presented to EDs relative to the rest of the adult population in metropolitan South Australia. Collectively, individuals within vulnerable groups were more likely to present to EDs and to have subsequent $\mathrm{ED}$ attendances than members of the wider community. Average RASC and Aboriginal presenters were notably younger and more likely living in disadvantaged areas compared with other presenters.

We stratified our analysis and examination of ACSC and GP-type presentations potentially suited to alternative primary and community healthcare interventions and showed differing patterns of ED use for each vulnerable group. We discuss each group's results in turn and reflect on areas of potential primary care response.

RASC presented at twice the rate of the wider population for acute and vaccine-preventable ACSC. Also, almost two-thirds of RASC presenters had GP-type presentations, with associated excess costs exceeding $\$$ A100 000 per 1000 population in the 6-year period. This segmented understanding ${ }^{36}$ of service use suggests newly arriving citizens have a capacity to benefit from assistance leading to improved health and health systems literacy, including health literacy on preventing infectious disease; familiarity with service alternatives ${ }^{37}$; and locating and accessing culturally secure primary care homes. ${ }^{38}$ The latter point is implicated in international studies ${ }^{39}$ and is a focus of the
Australian Healthcare Homes ${ }^{40}$ being piloted for patients with chronic and complex conditions. Our results suggest opportunities to broaden the focus of that new infrastructure by collaborating with existing Primary Health Networks to meet particular population group needs at potentially reduced cost.

Aboriginal people had comparatively higher presentation rates in all categories. They also had double the risk of multiple ED events generally, and for acute and chronic ACSC presentations. The greatest of these risks was associated with acute ACSC, the excess cost for which amounted to $\$ A 108000$ per 1000 population. A further $\$ A 53000$ per 1000 population was associated with chronic conditions. As with RASC, the findings reinforce a pervasive association of economic disadvantage ${ }^{41}$ with stress, crisis situations and emergency responses. ${ }^{42}$ Nevertheless and perhaps even more importantly, community healthcare centre developments which provide health-promoting and primary care services ${ }^{42}$ can be directly informed by RASC and Aboriginal peoples' insights. Each have positive assets and cultural strengths which can help identify appropriate forms of assistance and ways of constructively engaging people receiving care. ${ }^{43} 44$ This suggests the challenges of providing care to complex groups can be helped by improved communication among ED and hospital-based practitioners, primary care providers and the patients themselves. Two immediate actions in this regard include bringing representatives from each to meet outside the ED environment to share perspectives on preventative and alternative care strategies. Further, addressing the long-standing need for timely referral from ED to primary care practices, including copying patients into the pathway, remains a goal worth pursuing. ${ }^{45}$

Elevated presentation rates among older persons were influenced by acute conditions but dominated by multiple attendances for chronic ACSC. The latter accounted for one-seventh ( $\$$ A181 385 per 1000 population) of excess presentation costs. Collectively, this older group continues to grow in number and proportion of population. ${ }^{1}$ This makes the need for explicitly aligning primary care with client need ${ }^{40}$ all the more urgent in order to manage comorbidities and prevent or defer frailty among community-living older persons. ${ }^{46}$ Other promising intervention strategies include resourcing Local Health Networks, Primary Health Networks and general practice ${ }^{47}$ to carry out integrated, multidisciplinary ${ }^{48}$ care. Examples of such care include specialist review by community-based teams and even planned hospital stays to address complex needs in a controlled environment. Individuals with chronic, complex needs may also have long-term care relationships with GPs. Our method reports on the health system's willingness to increase hospital cost weightings where there is a high prevalence of comorbid conditions and the patient's needs are complex. A similar mechanism could be used in primary healthcare settings where those serving Aboriginal and older people could be incentivised to provide continuity of care, regular contact and comprehensive health checks. 


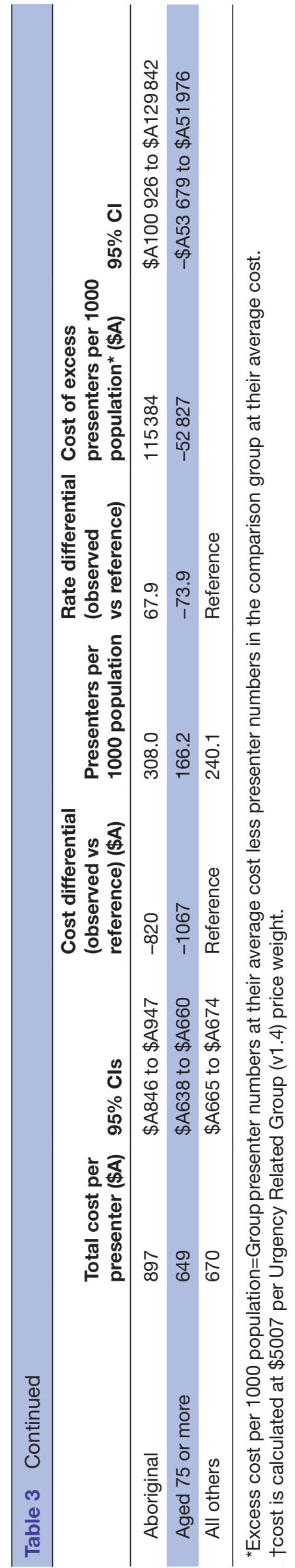

As such interventions are developed and put into operation, we in the research community have opportunities to support their successful evaluation. This support can include valid, reliable data and measurements encapsulating the needs of vulnerable groups using ED services. Such measures can also inform efficient resource allocations between, and within, healthcare sectors. The metrics and analysis in this study offer a start in both areas using existing administrative records. By focusing on individuals within their respective population group as the unit of analysis, we provided insight of who used ED services, the amount of use and the nature of that activity. This can help scope responses appropriate to those people and their circumstances while providing foresight on areas needing intervention. Accompanying person-level reporting with excess costs per population unit can help incentivise necessary change. In our particular case, we found excessive ED exposure costs for potentially preventable reasons approached $\$ A 4.5$ million per year. This is an amount sufficient to encourage meeting need in less costly, and hopefully more culturally suitable, primary or community care settings. Assessing the capacity to benefit from health interventions contributes to the first step of a continual learning approach focused on equitable, effective and efficient system change ${ }^{49}$ Subsequent steps in the process evaluate the gains and costs of alternative care options, and monitoring results once implementation decisions are taken.

The study was limited in a number of ways. The nature of ED administrative records is subject to misclassification bias. While the presenting condition is ICD-10 coded, it is subject to re-categorisation in any subsequent inpatient stay. Neither do hospital records describe individual socioeconomic positioning or, as particularly pertinent to our analysis, information on refugee or humanitarian entry to Australia. We also acknowledge our use of unadjusted analyses did not examine potential confounding from factors such as sex, age and socioeconomic position differences between groups. We consider this to be outside the scope of our immediate aim of describing who used ED services, for what reasons and at what cost. Other limitations arose from operationalising this particular study, for example, through the exclusion of one ED accounting for $10 \%$ of total presentations. Fortunately, that site is now available to future analyses of public hospital ED and further development of our preliminary enumeration in this area. We also omitted other vulnerable groups, for example homeless people, who remain invisible to analyses using administrative records. Nonetheless, more routine use of these data in planning and monitoring will encourage more complete data capture, including type of usual residence. The study also has a number of strengths. Our unit of analysis was unique persons ${ }^{9}$ which bolsters our understanding of the potential for redirecting patient-centred care. Moreover, we accompanied this information with direct, system costs related to individuals. Thus, we are also assisting with the assessment of both costs and benefits of 
resourcing alternative care for the benefit of individual persons within vulnerable populations.

Our approach and findings have direct relevance to other jurisdictions nationally and internationally wherever vulnerable populations exist and the responsibilities of providing appropriate care is taken seriously. For example, ascertainment of RASC is challenging. While our method offers an approach for quantifying adult RASC, enumerating RASC children who are recently born in Australia will require alternative methods. Our results support calls to pursue research activities that better enumerate RASC children as an emerging vulnerable group ${ }^{45}$ who will benefit from early, proactive interventions. Other research teams are innovating to reduce ED use by older Australians. ${ }^{48}$ Assimilating our personlevel reporting and estimation of direct costs will help inform decisions on prioritising effective interventions. Other opportunities to further develop our approach exist. These include analyses with an increased focus on individual measures of disadvantage that are amenable to change. This could involve the use of e-health records incorporating measures of health insurance status, primary care contacts and geocoded accessibility to care. Another opportunity is to take a broader view of ACSC hospitalisation by merging of ED and inpatient records. Such an approach would examine patterns of individuals' length of hospital stay across EDs and inpatient sites, together with their commensurate costs. ${ }^{50}$

\section{CONCLUSION}

We identified disparities in the relative frequency, nature and excess cost of ED contact by different vulnerable populations. A considerable number of ED presentations have the potential to be effectively prevented or addressed in other, lower-cost environments. This suggests inequities in the uptake of effective primary care and excess cost to the public hospital system. Enumerating vulnerable populations and service use in this way can inform person-centred care planning as a dimension of highquality care delivery.

Acknowledgements The authors thank SA Health for administrative unit records via Statistical Linkage Project 2010-0004.

Contributors DB conceived the project, performed the analyses and drafted the manuscript. KD contributed to literature searching and manuscript preparation. JK and JWL made important contributions to operationalising this study, interpreted the statistical analysis and revised the manuscript. All authors read and approved the final version of the manuscript.

Funding DB is supported in part by an Australian Government Research Training Program Scholarship.

Competing interests None declared.

Patient consent for publication Not required.

Ethics approval SA Health (467/08/2014) and the Aboriginal Health Council of South Australia (04-11-406) research ethics committees approved the study.

Provenance and peer review Not commissioned; externally peer reviewed.

Data sharing statement The study's data comprised de-identified unit record administrative records. These were used under privileged arrangements set out in a study-specific confidentiality deed. The data cannot be accessed by another party without relevant departmental and human research ethics approvals.

Open access This is an open access article distributed in accordance with the Creative Commons Attribution Non Commercial (CC BY-NC 4.0) license, which permits others to distribute, remix, adapt, build upon this work non-commercially, and license their derivative works on different terms, provided the original work is properly cited, appropriate credit is given, any changes made indicated, and the use is non-commercial. See: http://creativecommons.org/licenses/by-nc/4.0/.

\section{REFERENCES}

1. Burkett E, Martin-Khan MG, Scott J, et al. Trends and predicted trends in presentations of older people to Australian emergency departments: effects of demand growth, population aging and climate change. Aust Health Rev 2017;41:246-53.

2. Australian Institute of Health and Welfare. Emergency department care 2015-16: Australian hospital statistics. Canberra: AlHW, 2016. Report No.: Health services series no. 72. Cat. no. HSE 182.

3. Australian Bureau of Statistics. Estimates and Projections, Aboriginal and Torres Strait Islander Australians: 2001 to 2026. Canberra: ABS, 2014. Report No.: ABS Cat. 3238.0.

4. Freed GL, Gafforini S, Carson N. Age distribution of emergency department presentations in Victoria. Emerg Med Australas 2015;27:102-7.

5. Stephens AS, Broome RA. Patterns of low acuity patient presentations to emergency departments in New South Wales, Australia. Emerg Med Australas 2017;29:283-90.

6. Health SA. Transforming Health: Discussion Paper, 2014.

7. Jaeger MW, Ambadwar PB, King AJ, et al. Emergency care of children with ambulatory care sensitive conditions in the United States. J Emerg Med 2015;49:729-39.

8. McWilliams A, Tapp H, Barker J, et al. Cost analysis of the use of emergency departments for primary care services in Charlotte, North Carolina. N C Med J 2011;72:265-71.

9. Johnson PJ, Ghildayal N, Ward AC, et al. Disparities in potentially avoidable emergency department (ED) care: ED visits for ambulatory care sensitive conditions. Med Care 2012;50:1020-8.

10. Carter MW, Datti B, Winters JM. ED visits by older adults for ambulatory care-sensitive and supply-sensitive conditions. Am J Emerg Med 2006;24:428-34.

11. Chukmaitov AS, Tang A, Carretta HJ, et al. Characteristics of all, occasional, and frequent emergency department visits due to ambulatory care-sensitive conditions in Florida. J Ambul Care Manage 2012;35:149-58.

12. Fingar K, Barrett M, Elixhauser A, et al. Trends in potentially preventable inpatient hospital admissions and emergency department visits. Rockville, MD: Agency for Healthcare Research and Quality (US), 2015.

13. Gruneir A, Bell CM, Bronskill SE, et al. Frequency and pattern of emergency department visits by long-term care residents--a population-based study. J Am Geriatr Soc 2010;58:510-7.

14. Shah MN, Wasserman EB, Gillespie SM, et al. High-intensity telemedicine decreases emergency department use for ambulatory care sensitive conditions by older adult senior living community residents. J Am Med Dir Assoc 2015;16:1077-81.

15. Brownell J, Wang J, Smith A, et al. Trends in emergency department visits for ambulatory care sensitive conditions by elderly nursing home residents, 2001 to 2010. JAMA Intern Med 2014;174:156-8.

16. Caminal J, Starfield B, Sánchez E, et al. The role of primary care in preventing ambulatory care sensitive conditions. Eur J Public Health 2004;14:246-51.

17. Bezzina AJ, Smith PB, Cromwell D, et al. Primary care patients in the emergency department: who are they? A review of the definition of the 'primary care patient' in the emergency department. Emerg Med Australas 2005;17(5-6):472-9.

18. Australian Institute of Health and Welfare. Emergency department care 2011-12: Australian hospital statistics. Canberra: AlHW, 2012. Report No.: Health services series no. 45. Cat. no. HSE 126.

19. Health Performance Council. What's working, what's not: review of the South Australian Health System Performance for 2011-2014. Adelaide: Health Performance Council, 2014.

20. Health Performance Council Secretariat. Monitoring the implementation of Transforming Health Indicator Report. Adelaide: Government of South Australia, 2017.

21. Correa-Velez I, Sundararajan V, Brown K, et al. Hospital utilisation among people born in refugee-source countries: an analysis of hospital admissions, Victoria, 1998-2004. Med J Aust 2007;186:577-80. 
22. Correa-Velez I, Ansari Z, Sundararajan V, et al. A six-year descriptive analysis of hospitalisations for ambulatory care sensitive conditions among people born in refugee-source countries. Popul Health Metr 2007;5:1-8.

23. Hoon E, Pham C, Beilby J, et al. Unconnected and out-of-sight: identifying health care non-users with unmet needs. BMC Health Serv Res 2017;17:80.

24. Banham D, Woollacott T, Gray J, et al. Recognising potential for preventing hospitalisation. Aust Health Rev 2010;34:116-22.

25. Kirby SE, Dennis SM, Jayasinghe UW, et al. Patient related factors in frequent readmissions: the influence of condition, access to services and patient choice. BMC Health Serv Res 2010;10:216.

26. Mahmoud I, Hou XY. Immigrants and the utilization of hospital emergency departments. World J Emerg Med 2012;3:245-50.

27. Costa N, Sullivan M, Walker R, et al. Emergency department presentations of Victorian Aboriginal and Torres Straight Islander people. Health Inf Manag 2008;37:15-25.

28. Mazza D, Pearce C, Joe A, et al. Emergency department utilisation by older people in metropolitan Melbourne, 2008-12: findings from the Reducing Older Patient's Avoidable Presentations for Emergency Care Treatment (REDIRECT) study. Aust Health Rev 2018;42:181-8.

29. Institute of Medicine. Crossing the quality chasm: $A$ new health system for the 21st century, 2001.

30. Australian Bureau of Statistics. 3238.0.55.001-Estimates of Aboriginal and Torres Strait Islander Australians, 2013. June 2011. 30 August 2013.

31. Australian Bureau of Statistics. Statistical Geography Volume 1Australian Standard Geographical Classification (ASGC). Canberra: ABS, 2006. Report No.: Cat. no. 1216.0.

32. Australian Bureau of Statistics. Socio-Economic Indexes for Areas (SEIFA)-Technical Paper, 2011, 2013. Report No.: 2039.0.55.001.

33. National Casemix and Classification Centre (NCCC). The International Statistical Classification of Diseases and Related Health Problems Australian Modification (ICD-10-AM). Sydney: NCCC, Australian Health Services Research Institute, University of Wollongong, 2013.

34. Australian Institute of Health and Welfare. Australian hospital statistics 2012-13. Canberra: AlHW, 2014. Report No.: AlHW cat. no. HSE 145 (Health Services Series no. 54).

35. Independent Hospital Pricing Authority (IHPA). The Pricing Framework for Australian Public Hospital Services 2014-15. Darlinghurst: IHPA, 2014.

36. Hostetter M, Klein S. Segmenting Populations to Tailor Services, Improve Care. 2015 http://www.commonwealthfund.org/ publications/newsletters/quality-matters/2015/june/in-focus.
37. FitzGerald G, Toloo GS, Aitken P, et al. Public use and perceptions of emergency departments: a population survey. Emerg Med Australas 2015;27:336-42.

38. McCusker J, Roberge D, Lévesque JF, et al. Emergency department visits and primary care among adults with chronic conditions. Med Care 2010;48:972-80.

39. Ruud SE, Hjortdahl P, Natvig B. Reasons for attending a general emergency outpatient clinic versus a regular general practitioner-a survey among immigrant and native walk-in patients in Oslo, Norway. Scand J Prim Health Care 2017;35:35-45.

40. Jackson CL, Hambleton SJ. Australia's Health Care Homes: laying the right foundations. Med J Aust 2017;206:380-1.

41. Commonwealth of Australia Department of Health. My life, my lead-opportunities for strengthening approaches to the social determinants and cultural determinants of Indigenous health: report on the national consultations, 2017. December 2017.

42. Berchet C. Emergency care services: trends, drivers and interventions to manage the demand: OECD, 2015. Report No. Working Paper No. 83.

43. National Academies of Sciences Engineering and Medicine. Systems practices for the care of socially at-risk populations. Washington, DC: The National Academies Press, 2016.

44. Blueprint for a Post-2020 National Health Agreement. Australian Healthcare and Hospitals Association (AHHA): AHHA, 2017.

45. Yelland J, Riggs E, Szwarc J, et al. Improving the ascertainment of refugee-background people in health datasets and health services. Aust Health Rev 2018;42:130-3.

46. Puts MTE, Toubasi S, Andrew MK, et al. Interventions to prevent or reduce the level of frailty in community-dwelling older adults: a scoping review of the literature and international policies. Age Ageing 2017;46:383-92.

47. Productivity Commission. Shifting the dial: 5 year productivity review. Canberra: Productivity Commission, 2017. Report No: Report No. 84

48. Fan L, Lukin W, Zhao J, et al. Interventions targeting the elderly population to reduce emergency department utilisation: a literature review. Emerg Med J 2015;32:738-43.

49. Banham D, Lynch J, Karnon J. An equity-effectiveness framework linking health programs and healthy life expectancy. Aust J Prim Health 2011;17:309-19.

50. Banham D, Chen T, Karnon J, et al. Sociodemographic variations in the amount, duration and cost of potentially preventable hospitalisation for chronic conditions among Aboriginal and nonAboriginal Australians: a period prevalence study of linked public hospital data. BMJ Open 2017;7:e017331. 